\title{
Study on the Teaching of Advanced Mathematics in Cultivating Innovative Talents
}

\author{
Hongyi LI*, Hongjie LI \\ School of Mathematics and Systems Science, Beihang, Beijing 10011, China \\ *Corresponding author
}

\begin{abstract}
Advanced mathematics is a core curriculum in advanced education. The teaching of advanced mathematics needs to focus on developing students' innovative thinking and ability in order to meet the needs of talents in the current society. In this paper, we emphasize the importance of the interest-oriented teaching and the teaching of mathematical thought and methodology in the developing the students' creative thinking and innovation ability. Subsequently, we propose three practical teaching approaches for interest-oriented teaching, in order to motivate students' interests in learning. Correspondingly, we present three available approaches for the understanding of mathematical thought and methodology. For each approaches, we specify the working flow in detail through concrete examples, by using which we believe that the students could strengthen their training of thinking, and improve their innovative ability.

KEYWORD: Teaching methods of advanced mathematics; Innovative thinking and ability; Interest-oriented teaching; Mathematical philosophy and methodology; Mathematical modeling
\end{abstract}

\section{INTRODUCTION}

When asked "What qualities do scientists need", Wilhelm Conrad Röntgen, one of the most famous German physicians, once said that the first is Mathematics, the second is Mathematics and the third is still Mathematics. Therefore, it is obvious that the overall quality and innovation ability of an individual depend highly on the mathematical curriculum standards. Innovation is the soul for a nation to make progress, as well as an unexhausted source of its prosperity. The innovation and application of knowledge will be the core of the development of a society. Thus increasing the whole quality of our nation and cultivating innovative talents will be the key of the development of our country. On account of all above, it is then necessary to study on how to cultivate students' critical thinking and innovation ability.

Advanced Mathematics, one of the basic undergraduate courses with a tremendous amount of classic knowledge and contents, plays an important role in the college education system, considering that the majority of the freshmen should take it as an obligatory course and spend relatively a large amount of time and energy on it. The aim of this course is to cultivate students' mathematical philosophy, thinking and ability such as the logical thinking, spatial imagination, calculation, analysis and innovation [1]. In order to keep step with the development of the society and promote comprehensive development of students, teachers should understand the important role of cultivating innovative talents sufficiently, refresh the concept of teaching, reflect the characteristic of this course, and spare no efforts to explore how to develop students' innovation capability. That is, with all kinds of teaching methods, teachers should cultivate students' comprehensive ability of exploration, innovation, knowledge reorganization, and creation.

To achieve this goal, during the process of teaching, two aspects are critically important. The first one is that the teachers should pay more attention to the interest-oriented teaching. Considering the intrinsic of advanced mathematics such as high abstraction and indigestion, the undergraduate students may always feel little interesting in studying this course, let alone developing creative thinking and innovation ability. Thus, it is of great importance for teachers to carry on interest-oriented teaching method. The other critical aspect is to attach importance to students' understanding of mathematical philosophy and methodology. As the Chinese ancient proverb says, "Give a man a fish and you feed him for one day, while teach a man to fish and you feed him for a lifetime." The concepts and properties in advanced mathematics are like the fish, and the mathematical philosophy and methodology are the fishing skill. Students may forget the former quickly after their 
college life, but remember the later throughout their whole life. When encountering new problems in their practical work, they could still apply the mathematical philosophy and methodology to exploiting solutions, with few concrete definitions and formulations in mind. Therefore, teachers should bring in the mathematical philosophy and methodology during the teaching process.

To address these two aspects, in this paper we propose three available teaching approaches for the interest-oriented teaching and the understanding of mathematical philosophy and methodology, respectively. We illustrate the working flow of each approach in detail by using practical and relevant examples.

\section{ATTACH IMPORTANCE TO THE INTEREST- ORIENTED TEACHING}

In this section, we will focus on the interest-oriented teaching. We first emphasize its importance, and explain why we should attach importance to this aspect. Then, we propose three available approaches to implement this method: to combine teaching with stories, to combine theory with practice, and to use mathematical games in teaching, followed by detailed illustrations on each of these three approaches.

Being an extremely fundamental course, advanced mathematics has its own characteristics (i.e., a huge number of formulas, properties and theorems to memorize, most of which are abstract, hard to understand and deduce). Thus it makes a considerable number of students afraid of it, and even lose interests or enthusiasm towards it, which will cause great negative effect during the whole process of learning advanced mathematics. Whether students can study mathematics well or not depends on their enthusiasm and passion which are based on the true understanding of advanced mathematics. So interests-oriented teaching methods are the most effective motivation. Therefore, teachers should attach more importance to the process of teaching. Only in this way can students get interested in, appreciate and remember mathematical knowledge. Without abundant accumulation of knowledge, the cultivating of innovative talents is castle in the air.

How can teachers promote the students' interests towards advanced mathematics, which is an abstract course full of tedious facts, properties formulas and calculation, is an urgent problem to be solved. According to the long-time teaching experience of the authors, several approaches can be considered.

\section{1). Combine teaching with stories}

As we know, every fact or formula has its own background and anecdote. Therefore, when teachers have a good knowledge of mathematical history, stories and anecdotes of mathematicians, concepts, origins, development and comparison of ancient and modern mathematical methods, they will be available to rouse students' interests toward mathematics through telling stories, and even make students fascinated with it. Start the class with small stories is a wonderful method to promote students passion and rouse their interests, which will make the teaching process more smooth and efficient.

For example, when throwing light upon the concept of limit, the story of Cyclotomy created by H.Liu in ancient China is good enough to be included. The basic concept is that the more segments identified, the smaller the error. Thus the actual value will gradually close to the circumference ratio $\pi$. That is, the more number of edges of regular polygon are inscribed in a circle, the more accurate value of $\pi$ is. With the method of Cyclotomy, Liu started with regular hexagon inscribed in a circle, and double the numbers of edges like $12,24,48,96, \ldots$, to get the circumferences of each regular hexagon, so as to calculate $\pi$ with these circumferences. He ended with regular polygon with 3072 edges, and $\pi$ turns to be approximately 3.1416 . Liu was the first person to use theoretical method to calculate $\pi$, the results of which are 157/50 and 3921/1250. He is concerned as the outstanding representative of the idea of limit in ancient China.

\section{2). Combine theory with practice}

Mathematics is a subject with strong applicability, which is widely used in social life and production. One aim of teaching is to make students apply knowledge acquired in class to practice flexibly. Describing some actual scenes or applications through teaching will not only rouse students' interests, but also provide examples for students to get a deeper understanding of knowledge and finally remember them in mind. For example, some physical concepts or concepts in real life, such as speed and acceleration, can be introduced in the course of Calculus to enhance students' understanding of the derivative. What's more, some applications of Calculus are suitable for teaching as well. For example, economists use calculus to predict the trend of global economy; meteorologists use calculus to describe the air flow of the upper atmosphere; medical experts use calculus to design ultrasound and X-ray detection appliances to scan human internal organs. These applications include both unreal examples designed to explain some concepts, and actual examples from reality, making knowledge combine with practice and easier to understand.

\section{3). Use mathematical games}

It's very common in the history of mathematics 
that a large number of puzzling problems originated from those no more than amusement games. However, through working on the solutions of such problems with perseverance, many amazing mathematical thoughts appear. For example, Probability Theory originated from gambling. In $17^{\text {th }}$ century, a professional gambler in French named De Mailer asked Pascal for advice on how to properly distribute wagers, which are always considered in gambling. This problem is often referred to as the "problem of points". That is, of the two gamblers, the one who finishes accumulating a certain number of points first will win the game. The question is how they should allocate the bet before the end in order to win the game. Pascal and Fermat solved this problem independently in communication with each other.

Games can bring excellent effect in education, for not only can they motivate learners' interests, but also they are beneficial for cultivating mathematical thoughts, which can deepen students' understanding of mathematical concepts. For example, origami game, using a piece of square paper with creases on it, can reveal a large number of properties of geometric object and properties, such as similarity, axisymmetric, congruence, and proportion. Therefore, through the process of teaching, introducing games appropriately will not only enable students to gain mathematical knowledge and thoughts, but also help them develop right attitude towards study. In all, we can draw the conclusion game has significant value in mathematical education.

\section{ATTACH IMPORTANCE TO STUDENTS' UNDERSTANDING OF MATHEMATICAL PHILOSOPHY AND METHODOLOGY}

The essence of education is to cultivate talents, who should have a variety of qualities. While, one without innovation cannot be called a talent. If advanced mathematics, an important and basic course in advanced education, is only taken as a tool to lay the foundation for other courses, it is far from displaying its important functions. Instead, it should be considered as a training tool of innovative thinking by combining its principles and methods with computer technology to make full use of education of advanced mathematics [2].

When dealing with exercises in the textbook, a great number of students tend to refer to similar examples, without which they are not able to solve the problems with minor changes. This inflexibility reflects the students' inexperience in applying mathematical philosophy and methods.

Mathematical philosophy and methodology are the essence of mathematics, aiming at providing scientific approaches for solving problems and help students develop intelligence and innovation ability. Mathematical philosophy, often called mathematical philosophy and methodology, is the understanding of mathematical theory and the nature of its contents. And the mathematical methodology is the concrete way to use mathematical philosophy. These two things are the same in essence, between which the difference lies in the angle we choose when dealing with problems. In the process of establishing mathematical concepts, discovering mathematical facts, deducing mathematical theories and applying mathematical knowledge to practice, the philosophy and methodology summarized is the core of mathematics, which help student gather fragments of mathematical knowledge together to optimize the structure of mathematical knowledge system and construct mathematical cognition system. Through this way, they exert great influence on students' thoughts and overall quality, which will benefit students for the whole lifetime. The mathematical philosophy, which is the assembly of human intelligence, is broad and profound. As a general language and instrument, mathematics is not only a fundamental course, but also the principal approach of intelligence development and brain training, which is an effective approach to cultivate innovation [3].

Abundant mathematical philosophy and methodology exists in Advanced Mathematics. Therefore, based on scientific knowledge, teachers should guide students consciously to mine, refine and summarize the mathematical philosophy and methodologies implied in the textbook, and provide timely enhancement, conclusion and practice, which could finally help students grasp life-time beneficial philosophy and methodology and improve students' ability of innovation. In this way, students acquire not only a large number of mathematical concepts, approaches and conclusions, but also the spirit and methodology of mathematics, which will in turn develop students' interests towards mathematics and the ability of discovering, exploring, solving problems. This should be the purpose of the education of Advanced Mathematics.

In the process of teaching advanced mathematics, the teacher should reach the following points to attach more importance to mathematical philosophy and methodology.

\section{1). During the class, the teacher should pay more attention to the penetration of mathematical philosophy and methodology}

The formation of mathematical concepts, deduction and proof of conclusion, and the thinking process of solving problems are all excellent opportunities to penetrate mathematical philosophy and methodology and train students' thoughts. For example, when referring derivation on the composite function, there is a thought of "the whole and 
substitution" in the use of substitution approach of integral problems. When it comes to the problem about obtaining curved trapezoid area, there are mathematical philosophy and methodology of "mathematics combination", "approximate the curve by using straight lines " and "finite and infinite" of definite integral [4-6]. In this way, students not only obtain the mathematical knowledge, but there is the formation of mathematical philosophy and methodology in students' minds which lays the foundation for the students to master mathematics.

\section{2). Highlight and deepen mathematical philosophy and methodology through appropriate amount of practice}

To solve a mathematical problem, the guidance, employment, and innovation of mathematical philosophy and methodology are necessary. Similarly, the teaching of mathematics philosophy and methodology cannot be achieved without the practice of solving mathematical problems. Only when students are solving mathematical problems can they discover and consider problems and apply mathematical philosophy and methodology naturally. Therefore, teachers should help students sort out typical problems and make them do specific practices. For instance, teachers can find more problems with different solutions, which contain diverse mathematical approaches. In the process of comparing them, students will get a deeper understanding of these methods and master them better. Meanwhile, and exercise their divergent thinking [7-9].

\section{3). Combining mathematical modeling with mathematical teaching}

Mathematical modeling is a creative activity, and a quantitative measure to solve practical problems. Teachers construct corresponding practical questions for students by analyzing what mathematical knowledge students have acquired, and require students to use mathematical modeling to solve and evaluate these problems. Through practical experience, students will gradually discover and consider those problems, and finally relate them to the knowledge they have obtained, and make use of the mathematical approaches to solve them. Many mathematical modeling problems are open and do not have certain answers, which could cultivate the students' mindsets and ability, and excavate students' creativity. Students will often gain a sense of achievement when they put these mathematical approaches into use. In this way, it not only makes students have a deeper understanding of the nature of mathematics and enhance the interests of learning mathematics, but also improve their practical experience and cultivate the ability of innovative thinking.

\section{CONCLUSION}

The cultivation of innovative talents, which is the goal of advanced education, is crucial for the development of the society. Advanced Mathematics plays an important role in cultivating students' awareness and capability of innovation. In view of the advanced mathematics education, adopting proper teaching approaches to cultivate students' innovation ability is a difficult but significant task, which requires us to explore and innovate constantly in order to guarantee that approaches could satisfy the necessity of cultivating talents with international competitiveness. In this paper, we propose three available approaches to the interest-oriented teaching and the understanding of students on mathematical philosophy and methodology, respectively. By using these teaching processes, we believe that the students may benefit a lot in developing their creative thinking and innovation ability, which are the ingredients of talents in the current society.

\section{ACKNOWLEDGEMENT}

This work was supported by the National Nature and Science Foundation of China (Grant No. 61379001), and Key Project of Beihang University ("Exploration and Practice of Innovation Ability Cultivation in Mathematical Education”, Grant No. 201412).

\section{REFERENCES}

[1] F. Wei. The Exploration and Practice of Advanced Mathematics. College Mathematics, 2007, 23(6):6-9

[2] W.C. Wang. Promote the Innovation with the Feature of Advanced Mathematics. College Education Research, 2008, (14):237-239

[3] Y. Xu. Discussion about the Teaching of Mathematics and Cultivating Innovation thinking. Course Education, 2009, (26):83-84

[4] H.B. Zhang, J. Yang. Reflections on the Cultivation of Mathematical Abilities of Students. College Mathematics, 2003(4):88-89

[5] H.T. Li. Mathematics Teaching Design Based on "Problem Solving". Chinese Journal of Chemical Education, 2006(7):64-67

[6] Z.Q. Xin, L. Zhang. Mathematics Solving Actual Problems and Building Reality. Chinese Journal of Chemical Education, 2005(1):38-41

[7] S.Z. Li. Turn Abstract into Concrete- Construction of National Excellent Course. Chinese College Education, 2006(7):11-13

[8] H. Wang. The Training of Mathematical Research-Based Learning and Innovation. Chinese Journal of Chemical Education, 2006(7):68-78

[9] H.J. Xing, J.Y. Zhang, Q.M. Chen. A Debate of mathematics education between China and America and its Enlightenment. Chinese Journal of Chemical Education, 2007(2):50-53 